\title{
Adverse events after pleurodesis in patients with malignant pleural effusion
}

\author{
Ricardo Mingarini Terra ${ }^{1}$, Priscila Berenice da Costa ${ }^{1}$, Alberto Jorge Monteiro Dela Vega ${ }^{2}$, \\ Paulo Manuel Pêgo-Fernandes ${ }^{3}$
}

${ }^{1}$ Faculdade de Medicina FMUSP, Universidade de São Paulo, Sao Paulo, SP, Brazil; ${ }^{2}$ Instituto do Cancer do Estado de São Paulo, Hospital das Clinicas HCFMUSP, Faculdade de Medicina, Universidade de Sao Paulo, Sao Paulo, SP, Brazil; ${ }^{3}$ Instituto do Coracao, Hospital das Clinicas HCFMUSP, Faculdade de Medicina, Universidade de Sao Paulo, Sao Paulo, SP, Brazil

Contributions: (I) Conception and design: RM Terra, PM Pêgo-Fernandes; (II) Administrative support: PB Costa; (III) Provision of study materials or patients: RM Terra, AJM Dela Vega; (IV) Collection and assembly of data: RM Terra, AJM Dela Vega, PB Costa; (V) Data analysis and interpretation: RM Terra, AJM Dela Vega, PB Costa; (VI) Manuscript writing: All authors; (VII) Final approval of manuscript: All authors.

Correspondence to: Ricardo M. Terra. Hospital das Clinicas HCFMUSP, Faculdade de Medicina, Universidade de Sao Paulo, 44, Dr. Enéas de Carvalho Aguiar Avenue, B II, Room 9. Cerqueira Cesar, São Paulo, SP, Brazil. Email: rmterra@uol.com.br.

\begin{abstract}
Background: Malignant pleural effusion (MPE) is an important sign of advanced disease in metastatic cancer. Pleurodesis is one option to treat recurrent MPE. The Inflammatory response after pleurodesis may lead to important adverse events (AE) in a set of very ill patients.

Methods: Retrospective analysis of patients submitted to pleurodesis (2009-2013). Clinical and laboratory data were collected. We compare the values in the day of pleurodesis, $2^{\text {nd }}, 5^{\text {th }}$ and $10^{\text {th }}$ days after.

Results: One hundred fourteen patients were undergone to pleurodesis with silver nitrate (46\%), iodine (52\%) and talc (2\%). Female was the most frequent (86\%) and the breast cancer was the most common primary site. The most frequent adverse event was low hemoglobin account (37), followed by pain (31). 68\% of patients presented AEs and $28 \%$ had at least one AE with grade 3 or higher. The most altered was CRP that peaked in the $5^{\text {th }}$ day after pleurodesis. Changes in CRP curve were less severe with the use of iodine when compared with the other two agents.

Conclusions: Pleurodesis leads to important systemic inflammatory response detected by different serum markers. The occurrence of adverse events in this set of patients was great number of events with being marked as grade 3 or higher.
\end{abstract}

Keywords: Pleural effusion; pleurodesis; adverse effects

Submitted Dec 03, 2019. Accepted for publication Mar 12, 2020.

doi: $10.21037 /$ jtd-19-3850

View this article at: http://dx.doi.org/10.21037/jtd-19-3850

\section{Introduction}

Malignant pleural effusion (MPE) is a very disabling condition and markedly a sign of advanced disease. About $50 \%$ of patients with metastatic cancer develop MPE. In 2012 it was related to 126,825 admissions in the United States (1). The management of MPE is palliative and pleurodesis is one of the most common methods used to prevent a recurrence. Talc is the most used and studied agent but many other agents such as silver nitrate, tetracycline and iodopovidone have been tested over the years (2-4).

Pleural adhesions occur due to an important inflammatory response in the pleural space triggered by the presence of the sclerosing agent (5). Acute respiratory distress, fever, empyema, wound infections are described as frequent adverse events related to pleurodesis (5-7). Acute respiratory distress syndrome (ARDS) and Acute Lung Injury (ALI) related to pleurodesis are critical adverse events especially in this group of very ill patients already weakened 
by cancer. Some studies described incidences of ARDS and ALI as high as $9 \%$ and others suggest that the occurrence of ARDS may be rare and more associated with the particle size than with the pleurodesis effect itself (8-11).

Considering the importance of adverse events in the setting of frail patients with advanced cancer disease, we aimed at analyzing the occurrence of adverse events in subjects submitted to pleurodesis and the behavior of inflammatory markers after the procedure.

\section{Methods}

Retrospective analysis of the pleural diseases database of the University of São Paulo Thoracic Surgery Division. The database was set up in May 2009 and data collected in the current study are related to patients registered from its inception until June 2013. This study was approved by the institutional review board (Cappesq protocol number 3767/12).

We included patients with recurrent malignant pleural effusion confirmed by pleural fluid cytology or pleural biopsy, which underwent pleurodesis for the first time during the period of the study. Patients with no clinical information in their records were excluded. In our institution we used three different sclerosing agents, talc $(3 \mathrm{~g})$, silver nitrate $(0.5 \%, 30 \mathrm{~mL})$, and iodine $(2 \%$, $30 \mathrm{~mL}$ ), all instilled through a $24 \mathrm{Fr}$ chest tube or $14 \mathrm{Fr}$ pigtail catheter. Before the procedure, the patients were pre-medicated with opioids and intrapleural lidocaine. After pleurodesis patients received dipyrone and the tube was removed in 3 to 4 days in the absence of a large volume of drainage. We do not usually perform pleurodesis in patients with severe coagulation disorder, thrombocytopenia, kidney failure, pleural or systemic infection, and massive neoplastic infiltration on the skin.

To evaluate the systemic inflammatory reaction, serum tests were performed before pleurodesis, 2, 5, and 10 days after pleurodesis. The exams collected were: complete blood count, serum dosage of C-reactive protein (CRP), serum glutamic oxaloacetic transaminase (AST), serum glutamic pyruvic transaminase (ALT), alkaline phosphatase, $\gamma$-glutamyltranspeptidase (GGT), and renal function (urea and creatinine).

The adverse events (AEs) were quantified by the CTCAEV v.4.0 (12) questionnaire (Common Terminology Criteria for Adverse Events). This questionnaire classifies the AEs in degree: Degree 1: mild AR; Degree 2: Moderate AE; Degree 3: Severe AE; Degree 4: life-threatening or disabling AE; Degree 5: death related to the AE. AEs were recorded over the first 30 days after pleurodesis by trained researchers.

Categorical variables was expressed in frequencies and percentages. The continuous variables distribution were analyzed through graphical methods and the Shapiro-Wilk test and expressed as mean and standard deviation or median and interquartile range depending on their distribution. The Freidman's ANOVA test was used to evaluate repeated measures of serum markers before pleurodesis, 2, 5, and 10 days after pleurodesis. All inference analyses were twotailed and we considered statistical significance for those with $\mathrm{P}$ values $<0.05$. Box Plot was used to graphically represent the changes in laboratory findings after pleurodesis. Major statistics analysis and were performed using the software STATA version 13.0 (Stata Corp) and Friedman's ANOVA was calculated using SPSS (IBM Corp) version 25 .

\section{Results}

A total of 114 patients with MPE who have undergone pleurodesis were included in this study. The mean age was of $59 \pm 12$ years with a predominance of women $(85.9 \%)$ and the most common primary tumor type was breast cancer $(64.9 \%)$, followed by lung cancer $(16.6 \%)$. The demographic characteristics and results of pleural fluid are summarized in Table 1. The most used sclerosing agent was iodine $(51.7 \%)$ followed by silver nitrate $(46.4 \%)$ and talc $(1.7 \%)$. Four patients had a recurrence $(3.5 \%)$ and two had to be submitted to another pleurodesis procedure due to permanent high volume of drainage. Twelve patients $(10.5 \%)$ died before completing 30 days of treatment. After pleurodesis, 78 (68.4\%) patients presented adverse events and, of those, 31 (27.1\%) presented adverse events of degree 3 or higher. Table 2 describes the number of patients impacted by adverse events, and how frequent were events with grade 3 or more.

The most frequent adverse event of any grade was the decrease in the hemoglobin level with 37 events, followed by pain, an increase in creatinine level, and hypoxia. All the adverse events and the grades are described in Table 3.

All laboratory parameters presented important changes after pleurodesis. Only ALT didn't show statistical significance in repeated measures analysis. CRP was one of the most altered parameters and peaked at the $5^{\text {Th }}$ day. Figure 1 shows the laboratory findings on the day of the intervention (before pleurodesis), 2, 5, and 10 days after 
Table 1 Demographics and pleural fluid characteristics

\begin{tabular}{|c|c|}
\hline & Data \\
\hline Age & $59.11 \pm 12.71$ \\
\hline \multicolumn{2}{|l|}{ Gender } \\
\hline Male & $16(14 \%)$ \\
\hline Female & $98(85.9 \%)$ \\
\hline \multicolumn{2}{|l|}{ Primary tumor } \\
\hline Breast & $74(64.9 \%)$ \\
\hline Lung & $19(16.6 \%)$ \\
\hline Ovary & $6(5.2 \%)$ \\
\hline Unknown primary site & $4(0.5 \%)$ \\
\hline Lymphoma & $3(2.6 \%)$ \\
\hline GIT & $3(2.6 \%)$ \\
\hline Womb & $2(1.7 \%)$ \\
\hline Head and neck & $1(0.8 \%)$ \\
\hline Pancreas & $1(0.8 \%)$ \\
\hline Prostate & $1(0.8 \%)$ \\
\hline \multicolumn{2}{|c|}{ Pleural fluid characteristics } \\
\hline LDH (U/L) & $381.5(246-819)^{\star}$ \\
\hline Glucose (g/dL) & $100.8 \pm 46.2$ \\
\hline Protein (g/dL) & $4.3 \pm 0.95$ \\
\hline Nucleated cells $\left(\mathrm{mm}^{3}\right)$ & $880(370-1,450)^{\star}$ \\
\hline Lymphocytes (\%) & $90(75-95)^{\star}$ \\
\hline \multicolumn{2}{|l|}{ Oncotic cytology, n (\%) } \\
\hline Positive & $58(55.2 \%)$ \\
\hline Negative & $47(44.7 \%)$ \\
\hline
\end{tabular}

\pm standard deviation; LDH, lactic dehydrogenase; GIT, gastrointestinal tract. *Median (interquartile range).

the procedure. The variation in the CRP values changed depending on the agent used with higher levels associated with talc and silver nitrate. Figure 2 shows the curve for CRP categorized by the agent used.

\section{Discussion}

Our data showed that pleurodesis triggered an important systemic inflammatory reaction and led to a significant rate of adverse events. In our setting $68.4 \%$ of the subjects presented with at least 1 adverse effect of any grade and in
Table 2 Number of patients with recurrence and adverse events

\begin{tabular}{lc}
\hline & $\mathrm{n}(\%)$ \\
\hline Recurrence & $4(3.5 \%)$ \\
Death less than 30 days & $12(10.5 \%)$ \\
Adverse event & $78(68.4 \%)$ \\
Adverse event grade $\geq 3$ & $31(28.1 \%)$ \\
1 event & $22(70.9 \%)^{*}$ \\
2 events & $7(22.5 \%)^{*}$ \\
3 or more & $2(6.4 \%)^{*}$ \\
\hline *, percentages considering the number of patients with events \\
grade $\geq 3$.
\end{tabular}

$28.1 \%$ of the patients at least of on these $\mathrm{AE}$ was classified as severe (graded 3 or higher). Among the patients that presented with $\mathrm{AE}$ grade 3 or higher, there were significant incidences of hypoxia (17 events), severe pain (12 events), and the occurrence of 4 deaths clearly related to the procedure. There were 12 deaths within 30 days after the procedure what evince the critical condition of these sets of patients with metastatic disease. Although the elevation of leukocytes account and other inflammatory markers, the occurrence of infection was very low with only two cases including one case of pneumonia and one case of skin infection related to the insertion site (Table 3). These low number infection events match with recent studies that evaluate pleurodesis in comparison with Indwelling pleural catheters and early studies of pleurodesis (13-15).

Laboratory findings confirmed the relevance of the inflammatory response after pleurodesis as the $\mathrm{C}$-reactive protein (an important inflammatory marker) levels and Leukocytes account increased meaningfully. Platelet counts also have an important increase, especially in the $10^{\text {th }}$ after pleurodesis. This rise in the platelet count also emphasizes the magnitude of the systemic inflammatory response as platelets has been described as important responders to the inflammatory process (16). Other laboratory findings depicted that, besides the inflammatory stress, pleurodesis may also interfere with metabolic markers as ALT, AST, and Alkaline Phosphatase that peaked at $10^{\text {th }}$ day after pleurodesis with a statistically significant change in all but the ALT. The fall of the hemoglobin level after pleurodesis could be justified in part due to the drainage procedure albeit there was no record of important bleeding after the insertion of chest tubes that could justify this change.

The occurrence of adverse events after pleurodesis is 
Table 3 Adverse events and grade according to CTCAE v4.0

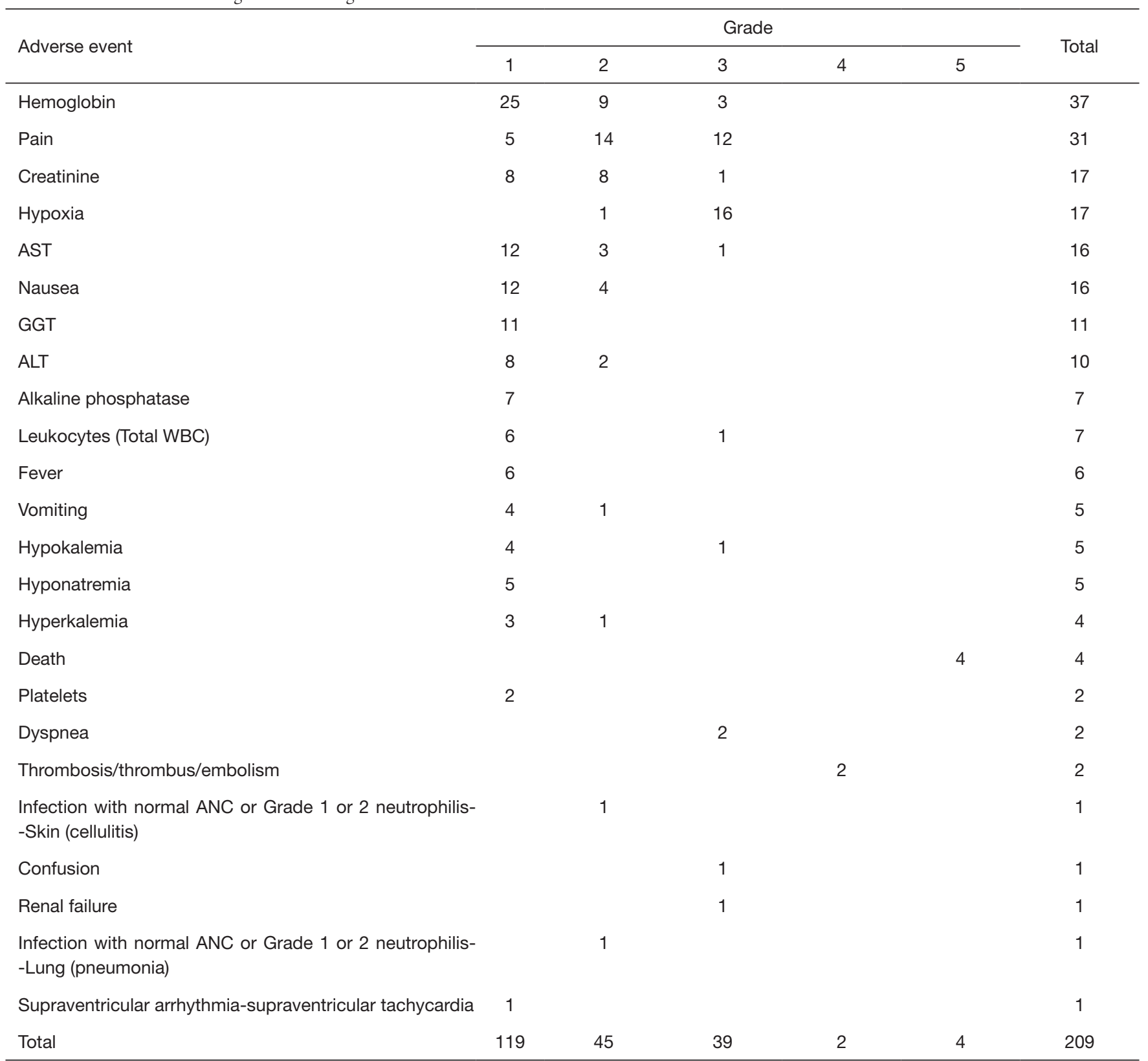

AST SGOT, serum glutamic oxaloacetic transaminase; ALT, SGPT serum glutamic pyruvic transaminase; GGT, y-Glutamyltranspeptidase; ANC, absolute neutrophil count; Platelets, thrombocytopenia; Hemoglobin, anemia.

described in the literature with different approaches. Xia et al. in a meta-analysis involving 1,525 patients reported pain, fever, and wound infection as the main adverse events (6). In an important prospective cohort of 558 patients submitted to thoracoscopic talc poundage pleurodesis Jansen and colleagues did not have an episode of acute distress syndrome, 7 patients had serious adverse effects and the mortality within 30 days was about $2 \%$ (10). The discussion of the safety of pleurodesis was driven in its majority by data from the decade of 1990 and early 2000s when important concern was raised about the occurrence of ARDS after pleurodesis $(11,17)$. Studies showed high rate of ARDS, Rehse et al. found 9\% of ARDS and other studies demonstrated the dissemination of talc to other organs 

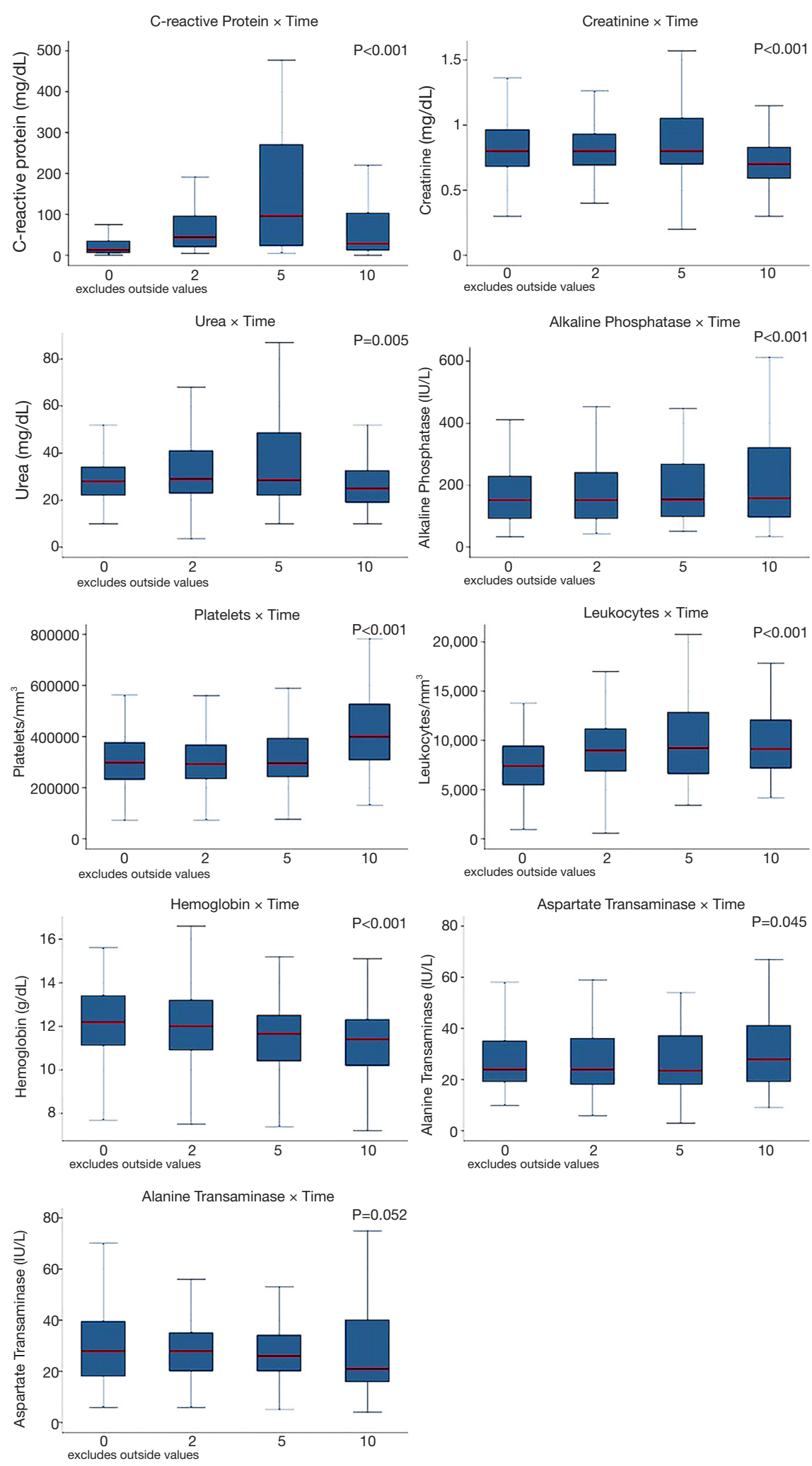

Figure 1 BOX plots depicting repeated measures of laboratorial findings at pleurodesis, day 2, day 5 and day 10 . Results of Friedman's ANOVA in the Upper Right-Hand Corner. 


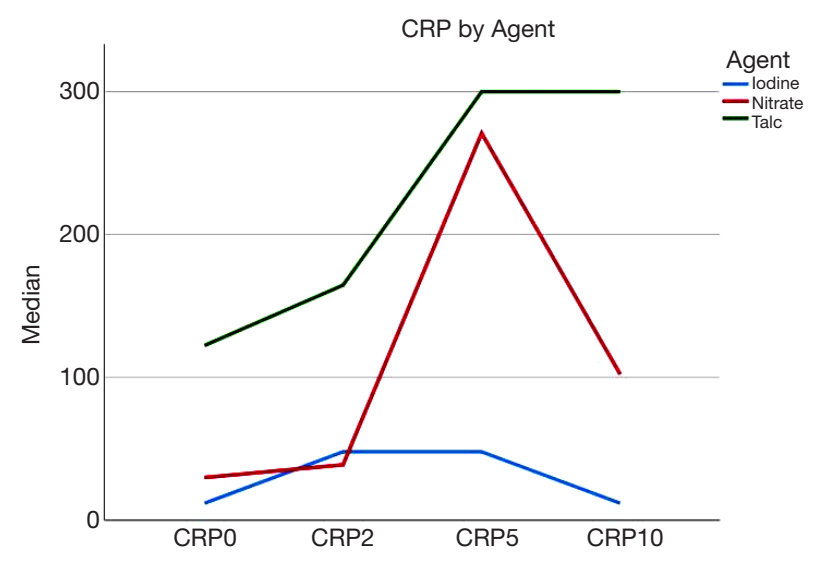

Figure $2 \mathrm{C}$-reactive protein (CRP) by agent in different periods of time. CRP0, CRP in time 0; CRP 2, CRP in day 2; CRP5, CRP in day 5; CRP10, CRP in day 10.

in human necropsy and in experimental studies $(9,18)$. Posterior reports revealed the role of the particle size in the development of inflammatory response in the lung and the safety of pleurodesis with talc $(10,19)$. In this dataset, there was no case of ARDS. The most frequent respiratory AE was hypoxemia that occurred in 17 cases 16 of which were grade as 3 which represents a decrease of $\mathrm{O} 2$ saturation at rest and need of continuous $\mathrm{O} 2$ supplementation. A possible explanation for this absence of ARDS in our study could be the few cases that used talc, as the size of talc particles may influence the occurrence of ARDS.

In the present study, we used 3 different agents for pleurodesis i.e., iodopovidone (50\%), silver nitrate (48.3\%), and Talc (1.3\%). Talc is the most studied agent and iodopovidone and silver nitrate were both alternatives with effectiveness and safety already studied $(3,20)$. This discrepancy between our profile of agents and the higher prevalence of talc in general practice can be explained by the availability of the agent in our hospitals during the development of the study what provides more external validity to our study considering the broad spectrum of agents available worldwide. It also allows us to describe the adverse events of agents not so frequently used. On the other hand, the use of silver nitrate and iodopovidone somehow hinders the comparison with studies that analyzed the only pleurodesis with talc. Notwithstanding the comparison between agents were not the objective of the study, our data showed that the curve of CRP changed substantially according to the agent used with a higher peak after the use of talc and silver nitrate when compared with iodine, as shown in Figure 2. This steadier curve of CRP represents a more moderate evolution of the most important inflammatory marker of the study. It may provide an advantage for iodine in the development of adverse events but the design of this study also does not allow us to make conclusions about the effectiveness and safety of agents separately.

\section{Conclusions}

Our data showed that pleurodesis significantly altered important inflammatory and metabolic markers reinforcing the hypothesis that pleurodesis leads to a substantive systemic inflammatory response and not only a local response. The high numbers of adverse events raise a concern about the risk-benefit of the procedure, even though adverse events graded as 3 or higher represented only $21.5 \%$ of all adverse events.

\section{Acknowledgments}

All the authors are grateful to the pleural research group and thoracic oncology. We would like to thank the Sao Paulo Research Foundation (FAPESP) for the scholarship provided (process number: 2009/50894-2).

Funding: None.

\section{Footnote}

Conflicts of Interest: All authors have completed the ICMJE uniform disclosure form (available at http://dx.doi. org/10.21037/jtd-19-3850). The authors have no conflicts of interest to declare.

Ethical Statement: The authors are accountable for all aspects of the work in ensuring that questions related to the accuracy or integrity of any part of the work are appropriately investigated and resolved. The study was conducted in accordance with the Declaration of Helsinki (as revised in 2013). This study was approved by the Ethics committee of our institution (CAPPesq No-3767/12). Informed consent was waived due to the retrospective nature of the study.

Open Access Statement: This is an Open Access article distributed in accordance with the Creative Commons Attribution-NonCommercial-NoDerivs 4.0 International License (CC BY-NC-ND 4.0), which permits the non- 
commercial replication and distribution of the article with the strict proviso that no changes or edits are made and the original work is properly cited (including links to both the formal publication through the relevant DOI and the license). See: https://creativecommons.org/licenses/by-nc-nd/4.0/.

\section{References}

1. Taghizadeh N, Fortin M, Tremblay A. US Hospitalizations for Malignant Pleural Effusions: Data From the 2012 National Inpatient Sample. Chest 2017;151:845-54.

2. Andrade Neto JD, Terra RM, Teixeira RM, et al. Safety Profile of the Use of Iodopovidone for Pleurodesis in Patients with Malignant Pleural Effusion. Respiration 2015;90:369-75.

3. Terra RM, Bellato RT, Teixeira LR, et al. Safety and systemic consequences of pleurodesis with three different doses of silver nitrate in patients with malignant pleural effusion. Respiration 2015;89:276-83.

4. Roberts ME, Neville E, Berrisford RG, et al. Management of a malignant pleural effusion: British Thoracic Society pleural disease guideline 2010. Thorax 2010;65:ii32-40.

5. Rodriguez-Panadero F, Montes-Worboys A. Mechanisms of pleurodesis. Respiration 2012;83:91-8.

6. Xia H, Wang XJ, Zhou Q, et al. Efficacy and safety of talc pleurodesis for malignant pleural effusion: A meta-analysis. PLoS One 2014;9:e87060.

7. Shaw P, Agarwal R. Pleurodesis for malignant pleural effusions. Cochrane Database Syst Rev 2004;(1):CD002916.

8. Kuzniar TJ, Blum MG, Kasibowska-Kuzniar K, et al. Predictors of Acute Lung Injury and Severe Hypoxemia in Patients Undergoing Operative Talc Pleurodesis. Ann Thorac Surg 2006;82:1976-81.

9. Campos JRM, Werebe EC, Vargas FS, et al. Respiratory failure due to insufflated talc. Lancet 1997;349:251-2.

10. Janssen JP, Collier G, Astoul P, et al. Safety of pleurodesis with talc poudrage in malignant pleural effusion: a prospective cohort study. Lancet 2007;369:1535-9.

11. Rehse DH, Aye RW, Florence MG. Respiratory failure following talc pleurodesis. Am J Surg 1999;177:437-40.

12. Nacional Cancer Institute (NCI); National Institutes of Health (NIH). Common Terminology Criteria for Adverse Events v4.0 (CTCAE). [Internet]. 2009. Available online: https://ctep.cancer.gov/protocolDevelopment/electronic_ applications/ctc.htm\#ctc_40

13. Boshuizen RC, vd Noort V, Burgers JA, et al. A randomized controlled trial comparing indwelling pleural catheters with talc pleurodesis (NVALT-14). Lung Cancer 2017;108:9-14.

14. Thomas R, Fysh ETH, Smith NA, et al. Effect of an indwelling pleural catheter vs talc pleurodesis on hospitalization days in patients with malignant pleural effusion: The AMPLE randomized clinical trial. JAMA 2017;318:1903-12.

15. Kennedy L, Rusch VW, Strange C, et al. Pleurodesis using talc slurry. Chest 1994;106:342-6.

16. Eisinger F, Patzelt J, Langer HF. The Platelet Response to Tissue Injury. Front Med (Lausanne) 2018;5:317.

17. de Campos JR, Vargas FS, De Campos Werebe E, et al. Thoracoscopy talc poudrage: A 15 -year experience. Chest 2001;119:801-6.

18. Werebe EC, Pazctti R, De Campos JRM, et al. Systemic distribution of talc after intrapleural administration in rats. Chest 1999;115:190-3.

19. Maskell NA, Lee YC, Gleeson FV, et al. Randomized trials describing lung inflammation after pleurodesis with talc of varying particle size. Am J Respir Crit Care Med 2004;170:377-82.

20. Andrade Neto JD, Terra RM, Teixeira RM, et al. Safety Profile of the Use of Iodopovidone for Pleurodesis in Patients with Malignant Pleural Effusion. Respiration 2015;90:369-75.
Cite this article as: Terra RM, da Costa PB, Dela Vega AJM, Pêgo-Fernandes PM. Adverse events after pleurodesis in patients with malignant pleural effusion. J Thorac Dis 2020;12(7):3507-3513. doi: 10.21037/jtd-19-3850 